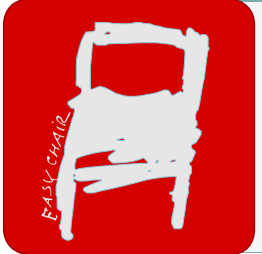

EPiC Series in Health Sciences

Volume 1, 2017, Pages 276-282

CAOS 2017. 17th Annual Meeting of the International

Society for Computer Assisted Orthopaedic Surgery

\title{
The effect of postoperative mechanical axis alignment of the revision rate of primary total knee arthroplasty after a follow up of 10 years
}

\author{
Je-Hyoung Yeo, Eun-Kyoo Song, Jong-Keun Seon, Dong-Hyun Lee \\ Center of Joint Disease, Chonnam National University Hwasun Hospital
}

\section{INTRODUCTION}

One long-term principle of total knee arthroplasty is that the overall postoperative limb alignment should be corrected to within $0^{\circ} \pm 3^{\circ}$ of the mechanical axis to promote implant durability [1,2]. However, in spite of the greater accuracy afforded by various modern implants and techniques, a substantial proportion of patients are not satisfied after TKA due to continued pain and poor function in daily living [3]. In addition, several recent studies have reported that there is no significant difference in survivorship when a traditionally held safe zone of mechanical axis of $0^{\circ} \pm 3^{\circ}$ is used to define well aligned versus mal-aligned knee [4]. However, most previous studies have reported that patients with neutrally aligned TKAs have improved clinical and functional outcomes [5].

Through reviewing all literatures and results, the fundamental assumption is that correction of the mechanical axis predicts the long-term durability of total knee implant. The hypothesis of this study was that the mechanical axis in the $0^{\circ} \pm 3^{\circ}$ range after surgery can represent better clinical results and lower revision rates that may affect long-term implant survival relative to post-operative mechanical axis beyond that range. 


\section{MATERIALS AND METHODS}

Between 2000 and 2006, clinical and radiographic data of 334 primary total knee arthroplasties were retrospectively reviewed to determine the 10 year Kaplan-Meier survival rate. Clinical outcomes were analyzed using scoring methods such as Range of Motions (ROM) assessment, Hospital for Special Surgery (HSS), Western Ontario \& McMaster Universities Osteoarthritis Index (WOMAC) score, and Knee Society Score (KSS) at preoperative and the final follow-up. Mechanical axis on coronal plane was measured on the standing full leg radiographs. Two groups were defined according to alignment angle of lower extremity. The first group was an acceptable group (AG) of 286 knees $\left(85.6 \%\right.$, with mechanical axis of $\left.0^{\circ} \pm 3^{\circ}\right)$. The second group was an outlier group (OG) of 48 knees $\left(14.4 \%\right.$, with mechanical axis of beyond $\left.0^{\circ} \pm 3^{\circ}\right)$. Postoperative complications and revision rates were also evaluated.

\section{RESULTS}

The mean degrees in the change of mechanical axis between immediate postop and last follow-up were greater in the outlier group $(1.6 \pm 2.7)$ than that in the acceptable group $(0.8 \pm 2.4)$. The revision rates were significantly $(P=.04)$ different between the two groups. The 10 year Kaplan-Meier survival analysis showed a tendency towards improved survival with restoration of neutral mechanical axis (Figure 1). However, such improvement was not statistically significant $(P=.25)$.

\section{DISCUSSION}

The present study supports that restoration of neutral alignment and traditional bone cutting are the most important factors during TKA for successful result. The acceptable alignment in the present study, like in most contemporary studies of alignment, showed a lower revision rate. This means that postoperative restoration of neutral alignment might be a required condition to prevent failure of the prosthesis. Several studies based on biomechanical $[6]$ and clinical $[5,7]$ results have shown that mal-alignment will result 
in higher failure rate with increased strain and worse functional outcomes. The principle of mechanically aligned TKA is to restore the neutral mechanical axis to improve the implant durability and patient's function following surgery. However, against our expectations, there were no significant differences in clinical outcomes between the AG and the OG.

Restoration of neutral limb alignment is a factor of total knee arthroplasty that can result in less revision rate and higher longevity. However, there are no significant differences in clinical outcomes between the two groups.

\section{REFERENCES}

1. Jeffery RS, Morris RW, Denham RA. Coronal alignment after total knee replacement. J Bone Joint Surg Br 1991;73(5):709.

2. Matziolis G, Krocker D, Weiss U, Tohtz S, Perka C. A prospective, randomized study of computer-assisted and conventional total knee arthroplasty. Three dimensional evaluation of implant alignment and rotation. J Bone Joint Surg Am 2007;89(2):236.

3. Bourne RB, Chesworth BM, Davis AM, Mahomed NN, Charron KD. Patient satisfaction after total knee arthroplasty: who is satisfied and who is not? Clin Orthop Relat Res 2010;468(1):57.

4. Song EK, Seon JK, Yoon TR, Park SJ, Cho SG, Yim JH. Comparative study of stability after total knee arthroplasties between navigation system and conventional techniques. J arthroplasty 2007;22(8):1107.

5. Longstaff LM, Sloan K, Stamp N, Scaddan M, Beaver R. Good alignment after total knee arthroplasty leads to faster rehabilitation and better function. J Arthroplasty 2009;24(4):570.

6. Bellemans J. Neutral mechanical alignment: a requirement for successful TKA: 
opposes. Orthopedics 2011;34(9):e507.

7. Mahoney $\mathrm{O}$. The role of alignment in TKR survivorship. Orthopedics today Hawaii 2010;10.

\section{DISCLOSURES}

This research did not receive any specific grant from funding agencies in the public, commercial, or not-for-profit sectors. 


\section{FIGURE}

Figure 1. Kaplan-Meier Survival Curve

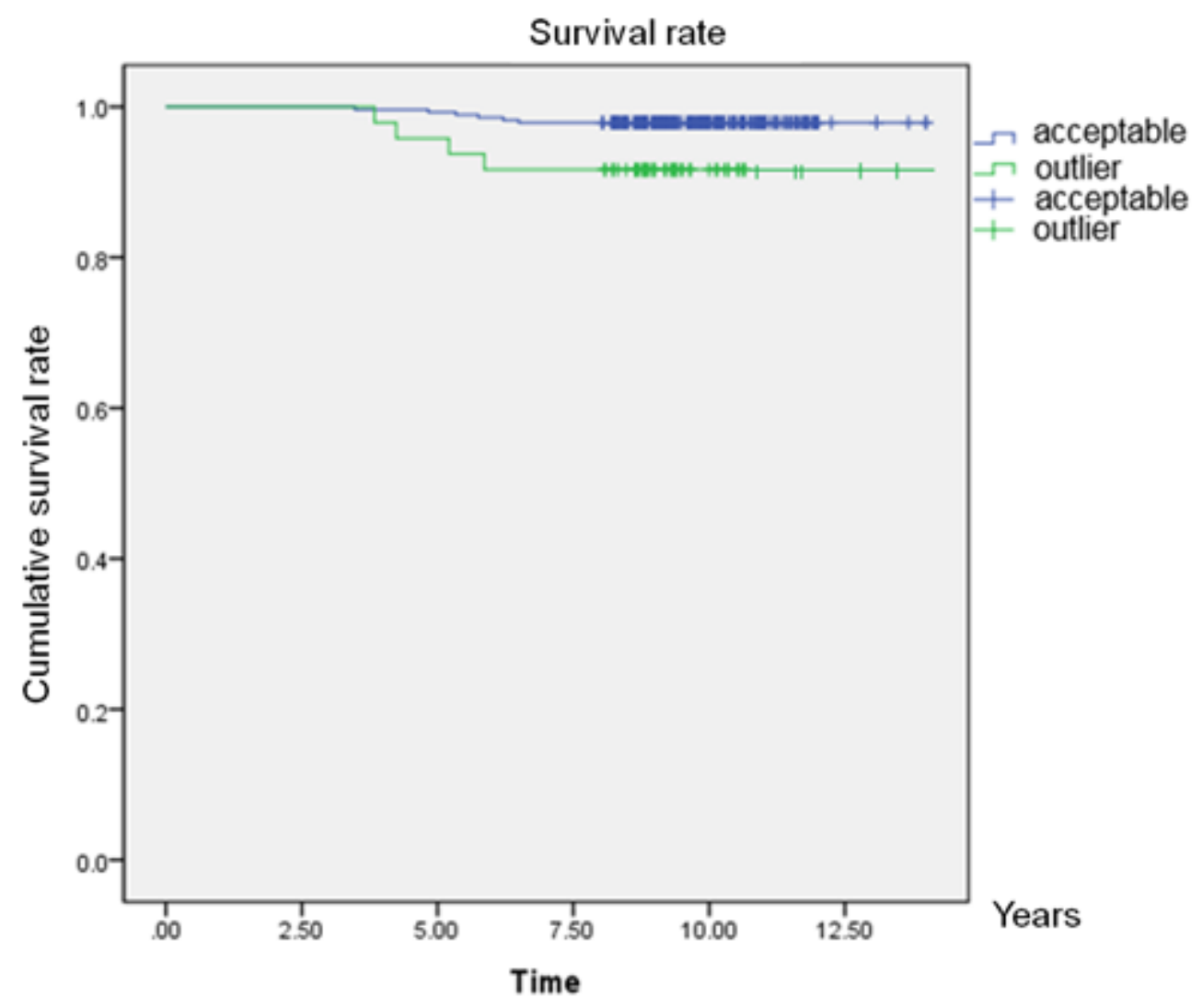




\section{TABLES}

Table 1. Clinical outcomes at the final follow up

\begin{tabular}{|l|c|c|c|}
\hline & $\leq 3$, Acceptable $(\mathrm{N}=286)$ & $>3$, Outlier, $(\mathrm{N}=48)$ & $P$-value \\
\hline ROM & $135.70 \pm 19.21$ & $132.25 \pm 15.21$ & 0.471 \\
\hline HSS & $90.65 \pm 9.63$ & $91.29 \pm 9.31$ & 0.243 \\
\hline WOMAC & $11.94 \pm 14.12$ & $11.70 \pm 10.71$ & 0.189 \\
\hline KSS (pain) & $46.23 \pm 8.82$ & $47.23 \pm 9.15$ & 0.497 \\
\hline KSS (function) & $86.73 \pm 13.27$ & $89.54 \pm 13.18$ & 0.195 \\
\hline
\end{tabular}

Table 2. Intergroup changes of mechanical axis transferred from each group

\begin{tabular}{|c|c|c|c|}
\hline & Acceptable $(\mathrm{N}=286)$ & Outlier, $(\mathrm{N}=48)$ & $P$-value \\
\hline Immediate postoperative & $0.74 \pm 1.66$ & $3.50 \pm 4.53$ & 0.000 \\
\hline Last follow up & $1.55 \pm 2.20$ & $5.13 \pm 3.62$ & 0.010 \\
\hline Interval change & $0.81 \pm 2.43$ & $1.63 \pm 2.70$ & 0.012 \\
\hline
\end{tabular}


Table 3. Postoperative complications in both groups

\begin{tabular}{|l|c|c|c|}
\hline & $\leq 3$, Acceptable $(\mathrm{N}=286)$ & $>3$, Outlier, $(\mathrm{N}=48)$ & $P$-value \\
\hline Aseptic loosening & $2(2$ revision) & 1 (1 revision) & 0.211 \\
\hline Instability & 4 & 1 (1 revision) & 0.211 \\
\hline PE wear & $2(2$ revision) & $2(2$ revision) & 0.330 \\
\hline PE breakage & $2(2$ revision) & 0 & 0.357 \\
\hline Periprosthetic $\mathrm{fx}$ & 2 & 0 & 0.326 \\
\hline \hline Total $(\mathrm{n}, \%)$ & $12(7.0 \%)$ & $4(10.4 \%)$ & 0.107 \\
\hline Revision rate $(\mathrm{n}, \%)$ & $6(2.1 \%)$ & $4(8.3 \%)$ & 0.041 \\
\hline
\end{tabular}

